RESIDENT

\& FELLOW

SECTION

Section Editor

Mitchell S.V. Elkind,

MD, MS

Laurence Morin, MD

Assia Smail, MD

Jean-Christophe Mercier,

$\mathrm{MD}, \mathrm{PhD}$

Luigi Titomanlio, MD, $\mathrm{PhD}$

Address correspondence and reprint requests to Dr. Luigi Titomanlio, Pediatric Emergency Dept., Robert Debré University Hospital, 48, Bld. Sérurier, 75019 Paris, France

luigi.titomanlio@rdb.aphp.fr

\title{
Clinical Reasoning: A child with pulsatile headache and vomiting
}

\section{SECTION 1}

A child was born to nonconsanguineous, healthy parents. Pregnancy and delivery were uneventful, and psychomotor development was normal. At the age of 6 years and 10 months, he was admitted to a local hospital because of vomiting and nonfebrile unilateral headache. Neurologic examination had normal results. Blood tests (complete blood count, C-reactive protein, electrolytes, blood urea nitrogen, creatinine, glucose, serum bicarbonate and $\mathrm{pH}$, anion gap, transaminase, and urine culture) were within normal limits. Abdominal $\mathrm{x}$-ray and abdominal ultrasound imaging had normal results. Based on these results and on clinical observation, common medical and surgical causes (viral illness, gastroenteritis, diabetes, intestinal obstruction) were ruled out. Head CT scan had normal results. The EEG showed some irregular activity in the occipital regions, with rare sharp waves, more prevalent on the right side. One week later, a further awake EEG was performed and had normal results. A presumptive diagnosis of migraine with aura was made after 2 months by a pediatric neurologist because of several episodes of unilateral pulsatile headache and vomiting (one to two episodes per week). The episodes were preceded by a sensation of sickness, and lasted about $5-10$ minutes each. Pallor, poorly defined abnormal ocular movements, and transitory unresponsiveness were also reported by his parents. After the episode, the child asked to sleep. Acetaminophen and ibuprofen were prescribed to control symptoms.

Five months later, the patient was brought to the Emergency Department of our hospital because of recurrent and long-lasting episodes of headache beginning the same day. He had four episodes of nausea, vomiting, pallor, and unilateral (right-sided or left-sided) pulsatile headache, each one lasting from 5 to more than 30 minutes. The prescribed treatment was ineffective, and the child was considered to be in a migraine aura status by his pediatrician.

A critical episode was observed during clinical examination: the child reported a sudden feeling of sickness and a severe unilateral pulsatile headache, followed by nausea. Left eyelid myoclonus followed, and the child described a short-lasting sensation of blindness. Then his head turned toward the right and he became unresponsive for about 20 seconds. Soon after, he vomited and became bradycardic (sinus rhythm, 35-40 bpm).

\section{Questions for consideration:}

1. What is the differential diagnosis?

2. What features of the history help make certain entities more or less likely? 


\section{SECTION 2}

The differential diagnosis in children presenting with pulsatile headache and vomiting, sensation of sickness, pallor, or other autonomic symptoms includes emergent etiologies such as intracranial mass (tumor, bleed, infection) and encephalitis, and non-emergent diseases such as migraine (mainly basilar migraine), gastroenteritis, vagal syncope, cyclic vomiting syndrome, intoxication, and partial seizures (occipital or temporal lobe epilepsy). Other rare etiologies to consider are vascular syndromes (Klippel-Trenaunay-Weber, arteriovenous malformations of the brain), familial dysautonomia (e.g., Riley-Day syndrome), breath-holding spells of early infancy progressing to isolated syncope, postural orthostatic tachycardia syndrome (POTS), and metabolic diseases. This child showed prolonged and severe autonomic symptoms (nausea, vomiting, pallor, bradycardia) that are mainly due to acute cerebral insults, but can also be diagnosed as status migrainosus or autonomic status epilepticus. In his personal history, we can identify shorter but similar episodes, suggesting that the two latter hypotheses are most likely correct. Migraine and epilepsy are highly comorbid conditions that may share the same pathophysiology, but the nature of their association is unclear. Our case does not fulfill the diagnostic criteria for migraine with aura of the International Classification of Headache Disorders, 2nd edition (ICHD-II). ${ }^{1}$ The aura, which can be visual, sensory, or dysphasic, is the consequence of focal cerebral dysfunction that immediately precedes or coincides with the headache onset. In our patient, autonomic symptoms could be related to a basilar-type migraine rather than to an aura. Differential diagnosis between seizure and migraine could be complicated by the presence of headache in both. Seizures can be followed by postictal headache (headache attributed to seizure, ICHD-II 7.6) and can also occur during or within 1 hour of a typical migraine aura attack (migraine-triggered seizure, ICHD-II 1.5.5). In migraineurs, interictal EEG findings are usually normal, although various abnormalities, including mainly diffuse slowing, have been reported. Sharp waves, observed in our patient, are not seen in migraine.

A clinical diagnosis of autonomic status epilepticus was made, and a rectal dose of $0.5 \mathrm{mg} / \mathrm{kg}$ of diazepam was administered, stopping the episode. The diagnosis of autonomic seizures is suggested by the episodic recurrence of unexplained vomiting or abdominal pain, migraine, or other autonomic symptoms, with EEG showing focal seizure activity.

The child fulfills the clinical and likely the EEG criteria for Panayiotopoulos syndrome (PS), a form of benign focal epilepsy of early childhood: several nonfebrile occipital seizures, occipital spike-wave activity at EEG (clinical history), absence of known etiologic factors, normal psychomotor development, and benign clinical evolution under treatment (when prescribed). PS is a common, benign, and idiopathic childhood autonomic epilepsy that has recently been incorporated into the international classification of epileptic syndromes. ${ }^{2}$ Of children aged 1 to 15 years who have had one or more nonfebrile seizures, PS affects approximately $6 \%$, and $13 \%$ of children aged 3 to 6 years. Age at onset is between 1 and 14 years with a peak between 4 and 5 years. Crises are focal, initially characterized by a complaint from the child of not feeling well, followed by autonomic signs or symptoms frequently characterized by emetic symptoms (nausea, retching, vomiting), paleness (or, less often, cyanosis or facial blushing), mydriasis (or, less often, miosis), coughing, hypersalivation, urinary and fecal incontinence, and cardiorespiratory and thermoregulatory alterations. ${ }^{3}$ In nearly all critical episodes, consciousness is initially intact. During seizure evolution, the child can become flaccid and unresponsive in $20 \%$ of cases (ictal syncope), with tonic eye and head deviation. Headache is often concurrent with other autonomic symptoms. Speech arrest, visual hallucinations, oropharyngolaryngeal movements, and behavioral disturbances occur less frequently. Autonomic seizures in PS are frequently prolonged, more than 30 minutes in nearly half of cases (autonomic status epilepticus). ${ }^{4}$

In PS, the neuroanatomic and neurophysiologic pathways involved in the generation of autonomic signs are unknown. Usually, autonomic manifestations are generated by activation or inhibition of parts of the central autonomic network that involves the insular cortex, medial prefrontal cortex, amygdala, hypothalamus, and ventrolateral medulla. In PS, the epileptogenic zone is wide and bilateral. Therefore, ictal discharges may easily activate the lower threshold autonomic centers. In children with PS, autonomic manifestations also may be attributed to a maturation-related susceptibility of the central autonomic network. ${ }^{5}$ Seizures remain purely autonomic if ictal neuronal activation of non-autonomic cortical areas fails to reach the threshold to produce other symptoms; otherwise autonomic and localizationrelated cortical symptoms occur.

The child had a complete recovery and was kept under medical supervision for 1 day. No more episodes occurred.

\section{Questions for consideration:}

1. What testing would you obtain at this point to confirm the diagnosis?

2. What is the prognosis for this patient?

3. Would you prescribe a treatment, and, if yes, which one? 


\section{SECTION 3}

Interictal EEG testing was repeated to confirm the EEG criteria for PS, and it showed independent bilateral occipital spike-wave complexes. Brain MRI had normal results. Antiepileptic therapy was started (valproic acid, $20 \mathrm{mg} / \mathrm{kg} / \mathrm{day}$ ). At 8 years and 4 months of age, he remained symptom-free.

An awake and asleep EEG is the only investigation that commonly shows abnormal results (90\% of cases). The epileptiform activity is characterized by spikes or spike-wave complexes of great amplitude, with multifocal localization predominating in the posterior regions. ${ }^{6}$ Interictal EEG findings show intraindividual variability. ${ }^{5}$ High-resolution brain MRI has normal results. The overall prognosis of PS is excellent, with remission usually occurring within 1 or 2 years after onset. Children have normal physical and neuropsychological development and the risk of epilepsy in adult life appears no higher than in the general population. Treatment might not be necessary because in one-third of cases there is only a single seizure, but benzodiazepines, administered by IV, rectal, or buccal preparations, are commonly used to terminate autonomic status epilepticus. Whereas PS is benign in terms of long-term evolution, autonomic seizures can be associated with potentially lifethreatening cardiorespiratory arrest and death. ${ }^{7}$ To date, therapeutic management of PS and autonomic status epilepticus is based on consensus. There is no evidence of the superiority of any antiepileptic drug, and carbamazepine and valproic acid are both widely used. ${ }^{8}$ If antiepileptic treatment is started, it is suggested to consider its withdrawal within 2 years. Because of autonomic status epilepticus and bradycardia in our patient, valproic acid therapy was started and symptoms resolved completely.

DISCUSSION Diagnosis of autonomic status epilepticus can be difficult, especially if this possibility is not considered by the clinician in an emergency setting. Most general practitioners and pediatricians are not familiar with the notion that prominent autonomic symptoms and signs may occur as epileptic seizure manifestations of occipital origin. As a consequence, this diagnosis can be easily missed and have potentially lifethreatening sequelae. ${ }^{9}$ Detecting key symptoms usually associated with PS may prevent erroneous diagnoses, shorten the length of clinical observation, and prevent unnecessary investigations. Early recognition of PS can also provide rapid reassurance to families in situations that can be very alarming.

Cardiovascular changes in PS have received the most attention, probably because of their possible contribution to sudden death in these patients. ${ }^{7}$ The association between seizures and heart rate changes has already been documented in several studies, tachyarrhythmias being more common than bradyarrhythmias. Ictal bradycardia is seen primarily in association with focal seizures, particularly involving the temporal and limbic lobes. ${ }^{10}$ Conversely, there are very few cases of ictal cardiorespiratory arrest reported in $\mathrm{PS}^{7}$; therefore, its best management is unclear. In our case, an intrarectal dose of diazepam was rapidly effective in normalizing heart rate, possibly preventing a cardiorespiratory arrest, with all its consequences.

CONCLUSIONS PS often eludes diagnosis as it presents with manifestations that could be overlooked and symptoms that are frequently mistaken for more common childhood disorders (migraine in the present case). The risk of cardiorespiratory arrest in PS should be known by practitioners in clinical emergency medicine. Some children have been reported to be resuscitated, intubated, and mechanically ventilated as a consequence of PS attacks. Our case illustrates the efficacy of an intrarectal dose of diazepam in case of ictal bradycardia, possibly preventing a cardiorespiratory arrest. Although more studies are needed on the subject, supportive family management should also include specific education about autonomic status epilepticus symptoms.

\section{REFERENCES}

1. International Classification of Headache Disorders, 2nd edition. Cephalalgia 2004;24 suppl 1:9-160.

2. Covanis A, Panayiotopoulos CP. Improving the diagnostic yield in Panayiotopoulos syndrome. Eur J Neurol 2008; 15:317-319.

3. Panayiotopoulos CP. Autonomic seizures and autonomic status epilepticus peculiar to childhood: diagnosis and management. Epilepsy Behav 2004;5:286-295.

4. Dura-Trave T, Yoldi-Petri ME, Gallinas-Victoriano F. Panayiotopoulos syndrome: epidemiological and clinical characteristics and outcome. Eur J Neurol 2008;15:336-341.

5. Panayiotopoulos CP, Michael M, Sanders S, et al. Benign childhood focal epilepsies: assessment of established and newly recognized syndromes. Brain 2008;131:2264-2286.

6. Ferrie C, Caraballo R, Covanis A, et al. Panayiotopoulos syndrome: a consensus view. Dev Med Child Neurol 2006;48:236-240.

7. Verrotti A, Salladini C, Trotta D, et al. Ictal cardiorespiratory arrest in Panayiotopoulos syndrome. Neurology 2005;64:1816-1817.

8. Caraballo R, Cersosimo R, Medina C, Fejerman N. Panayiotopoulos-type benign childhood occipital epilepsy: a prospective study. Neurology 2000;55:1096-1100.

9. Covanis A. Panayiotopoulos syndrome: a benign childhood autonomic epilepsy frequently imitating encephalitis, syncope, migraine, sleep disorder, or gastroenteritis. Pediatrics 2006;118:e1237-1243.

10. Schuele SU, Bermeo AC, Alexopoulos AV, et al. Videoelectrographic and clinical features in patients with ictal asystole. Neurology 2007;69:434-441. 


\section{Neurology}

\section{Clinical Reasoning: A child with pulsatile headache and vomiting}

Laurence Morin, Assia Smail, Jean-Christophe Mercier, et al.

Neurology 2009;72;e69-e71

DOI 10.1212/01.wnl.0000346690.84004.af

\section{This information is current as of April 13, 2009}

\section{Updated Information \&} Services

References

Subspecialty Collections

Permissions \& Licensing

Reprints including high resolution figures, can be found at: http://n.neurology.org/content/72/15/e69.full

This article cites 10 articles, 3 of which you can access for free at: http://n.neurology.org/content/72/15/e69.full\#ref-list-1

This article, along with others on similar topics, appears in the following collection(s):

Migraine

http://n.neurology.org/cgi/collection/migraine

Partial seizures

http://n.neurology.org/cgi/collection/partial_seizures

Pediatric headache

http://n.neurology.org/cgi/collection/pediatric_headache

Status epilepticus

http://n.neurology.org/cgi/collection/status_epilepticus

Syncope

http://n.neurology.org/cgi/collection/syncope

Information about reproducing this article in parts (figures,tables) or in its entirety can be found online at:

http://www.neurology.org/about/about_the_journal\#permissions

Information about ordering reprints can be found online: http://n.neurology.org/subscribers/advertise

Neurology ${ }^{\circledR}$ is the official journal of the American Academy of Neurology. Published continuously since 1951, it is now a weekly with 48 issues per year. Copyright . All rights reserved. Print ISSN: 0028-3878. Online ISSN: 1526-632X.

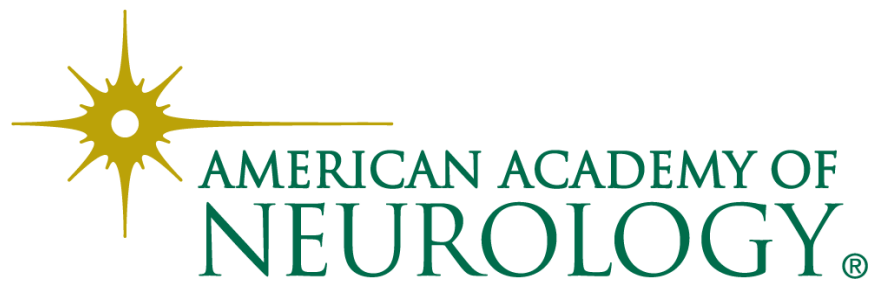

